\title{
The influence of organisational changes on cost efficiency in fire and rescue services
}

\author{
Johan Holmgren and Åsa Weinholt \\ Journal Article
}

\section{Tweet}

N.B.: When citing this work, cite the original article.

Original Publication:

Johan Holmgren and Åsa Weinholt, The influence of organisational changes on cost efficiency in fire and rescue services, International Journal of Emergency Management, 2016. 12(4), pp.343-365.

http://dx.doi.org/10.1504/IJEM.2016.10000713

Copyright: Inderscience

http://www.inderscience.com/

Postprint available at: Linköping University Electronic Press

http://urn.kb.se/resolve?urn=urn:nbn:se:liu:diva-132247

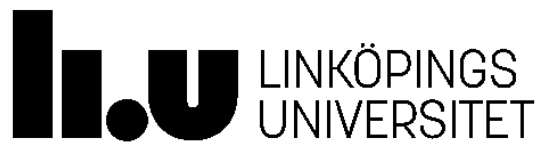




\title{
The Influence of Organizational Changes
} on Cost Efficiency in Fire and Rescue

\section{Services}

\author{
Johan Holmgren* \\ Faculty of Logistics, Molde University College - Specialized University in Logistics, \\ Norway \\ E-mail: johan.holmgren@himolde.no \\ ${ }^{*}$ Corresponding author
}

Åsa Weinholt

Division of Communications and Transport Systems, Department of Science and Technology, Linköping University, Sweden

E-mail: asa.weinholt@liu.se

\begin{abstract}
Fire and rescue services (FRS) in Sweden have recently undergone organizational changes aiming at improving service quality and efficiency. Among those changes are an increased number of formalized cooperations between FRSs in neighboring municipalities, increased collaboration with other sectors in day-today operations, changes in the structure of rescue teams, and an increase in the tasks performed by the services. The purpose of this study was to evaluate whether these policy changes have resulted in increased cost efficiency in the Swedish FRS. We used stochastic frontier analysis of annual data from 2009 to 2012 for 205 Swedish municipalities, taking into account the relevant differences in conditions among them. The conclusion is that there is no evidence to be found of improved efficiency in the FRS. The policy changes that have been implemented have not had the desired effects, and most of the policy variables tested for inclusion in the model were not found significant. The results also show great variation in efficiency between FRAs which could be used for benchmarking and basis for further analysis.
\end{abstract}

Keywords: Fire and rescue services, Stochastic frontier analysis, Efficiency evaluation, Benchmarking, Cost, Production 


\section{Introduction}

In a time when the fiscal environment is becoming harsher for many countries, the need for efficient use of public funds is apparent. Measuring efficiency and productivity in the public sector has therefore increased in popularity, and there is evidence of a "performance movement" in the sector; more emphasis is put on measuring how well different sectors perform and how firms within a sector perform in comparison with other firms (Poister 2008).

However, in some sectors, such as the fire and rescue services (FRS), it can be hard to find appropriate data that enable such evaluations. Another difficulty is to determine what the FRS actually produce (Jaldell 2002). The number of studies evaluating efficiency in FRS is therefore still quite small in comparison with other sectors (see Jaldell 2002, Ahlbrandt 1973, Kristensen 1983, Bouckaert 1992, Choi 2005, Peng M et al. 2014). Ahlbrandt (1973) compared differences in efficiency between private and public FRS suppliers in the state of Washington, USA and concluded that private suppliers had lower costs than public suppliers. The same conclusion was reported by Kristensen (1983), making similar comparisons in Denmark. Bouckaert (1992) compared Belgium FRSs and found that professional services were more efficient than mixed services (FRSs with both part-time and full-time firefighters) or volunteer fire services, since they spent more effort on preventive activities. Choi (2005) compared the relative efficiency of FRSs in Florida to show how benchmarking (the systematic comparison of the performance of one firm against other firms) can be used by decision makers to evaluate weaknesses and strengths in the industry.

Jaldell (2002) studied FRSs in the Swedish context over the period 1989-1997 and concluded that the efficiency level in the services was low: about $70 \%$ of potential capacity. Peng et al. (2014) made an international comparison of the efficiency of FRSs and observed that the FRS in Sweden needed to become more efficient by increasing economies of scale.

The need for greater efficiency in the Swedish FRS has not only been noticed in academia but has also been an issue for debate among practitioners. Fire managers in Sweden have experienced difficulties in obtaining the resources necessary to operate, and the need to make the FRS more efficient (same output at lower cost, or more and/or higher quality output at same cost) has become apparent within the industry (Rosenberg 2001). This has resulted in a number of organizational changes aimed at improving efficiency and service quality in the FRS over the last decade. These changes may be summarized as follows:

- There are more formalized cooperations between FRSs in neighboring municipalities.

- There are more collaborations with other sectors.

- There have been changes in the structure of rescue teams.

- The number of tasks performed by the FRS has increased.

The meaning of these changes, their goals and to what extent they have been implemented and studied before will be further described in section 2 . However, the effects on cost efficiency in the 
FRS from these initiatives have not been studied previously. The purpose of this study is therefore to examine whether cost efficiency in the FRS in Sweden has been affected by the described organizational changes that have been implemented in a large number of FRSs over the last decade.

Efficiency, in general terms, can be defined as attaining the highest possible output with a given amount of input or producing a given level of output at the lowest possible cost. An important part of the study, therefore, is to define appropriate measures of output. In order to do this, previous work on this problem will be reviewed, and previously used output measures will be linked and compared to those used in the present study. To provide a basis for benchmarking and an assessment of overall industry efficiency, the study will also provide a ranking of Swedish municipal FRSs in terms of efficiency.

The paper is divided into three main parts. The first part focuses on describing the FRS in Sweden and the underlying causes of the implemented changes. The second part describes a production and cost model for the FRS as developed in previous studies, here we also introduce the evaluation approach of the study: stochastic frontier analysis (SFA). In the third part of the paper, we present the empirical analysis, based on annual data from 205 Swedish municipalities from 2009 to 2012. Results are presented and discussed and possible explanations provided with a discussion on the usefulness of the model developed in this study.

\section{Fire and Rescue Services in Sweden}

In Sweden, FRSs are a municipal responsibility. Municipalities are required by law to guarantee that rescue operations begin within an acceptable time and are managed in an efficient manner (SFS 2003:778). ${ }^{1}$ Sweden has 290 municipalities with an average of 32,000 inhabitants. The variations in population are large; 140 municipalities have less than 15,000 inhabitants, and 40 municipalities have more than 70,000 inhabitants. The municipalities also differ considerably in area, from $8 \mathrm{sq} . \mathrm{km}$ to 20,000 sq. $\mathrm{km}$, and there are many sparsely populated areas, thus making it hard to provide an equal supply of protection to the citizens. This results in great differences in response time ${ }^{2}$ across municipalities; in 2012, the median response time ranged from 7 minutes to 34 minutes. The costs for the FRS also vary: in 2012, the cost per inhabitant varied from 282 SEK to 6249 SEK.

Table 1 shows the average cost per inhabitant in 2012 for small, medium, and large-sized municipalities. ${ }^{3}$ As can be expected, the number of turnouts and fires per 1000 inhabitants also differs among municipalities. In the larger municipalities, the standard is to have full-time firefighters or a mix of full-time and part-time firefighters. In the smaller municipalities, the proportion of part-time firefighters is higher than in the larger ones (see Table 1). Full-time firefighters have in general

\footnotetext{
${ }^{1}$ The law does however not specify what an acceptable time is and what is meant by "efficient manner".

${ }^{2}$ The response time is the time between the alarm, reaching the FRS, and the crew reaching the incident site.

${ }^{3}$ A small municipality is defined as having less than 15,000 inhabitants; a medium-sized municipality as having between 15,000 and 70000 inhabitants, and a large municipality as having more than 70,000 inhabitants.
} 
undergone longer training and acquired more experience than part-time firefighters. However, the major difference is that a full-time fire crew has a preparation time about five minutes shorter than that of a part-time crew since the part-time firefighters are either at home or at their main place of work when they receive the alarm (Juås and Mattsson 1997).

Table 1. Comparison of the means of key variables divided on small, medium-sized, and large municipalities in 2012.

\begin{tabular}{|c|c|c|c|c|}
\hline & $\begin{array}{l}\text { Small-sized } \\
\text { municipalities } \\
(n=139)\end{array}$ & $\begin{array}{l}\text { Medium-sized } \\
\text { municipalities } \\
(n=121)\end{array}$ & $\begin{array}{l}\text { Large-sized } \\
\text { municipalities } \\
(n=26)\end{array}$ & $\begin{array}{l}\text { Overall } \\
(n=290)\end{array}$ \\
\hline $\begin{array}{l}\text { Cost per year: } \\
\text { per capita spending } \\
\text { for FRS }\end{array}$ & 1045 SEK & 845 SEK & 609 SEK & 917 SEK \\
\hline $\begin{array}{l}\text { Total nr of turnouts } \\
\text { per } 1000 \text { inhab. }\end{array}$ & 11.558 & 10.016 & 8.965 & 10.641 \\
\hline $\begin{array}{l}\text { Total nr of fires per } \\
1000 \text { inhab. }\end{array}$ & 1.545 & 1.186 & 0.979 & 1.335 \\
\hline $\begin{array}{l}\text { Part-time workers per } \\
1000 \text { inhab. }\end{array}$ & 3.370 & 1.351 & 0.610 & 2.244 \\
\hline $\begin{array}{l}\text { Full-time workers per } \\
1000 \text { inhab. }\end{array}$ & 0.284 & 0.607 & 0.534 & 0.445 \\
\hline $\begin{array}{l}\text { Prevention: } \\
\text { nr of workers per } \\
1000 \text { inhab. }\end{array}$ & 0.076 & 0.0638 & 0.0472 & 0.068 \\
\hline Response time & $17.962 \mathrm{~min}$ & $13.457 \mathrm{~min}$ & $11.95 \mathrm{~min}$ & $15.410 \mathrm{~min}$ \\
\hline
\end{tabular}

The routines for managing turnouts in the Swedish FRSs have been more or less similar across municipalities despite the large differences among them. When the FRS receives an alarm, the standard has been to send four firefighters and one unit leader to the incident site, regardless of the severity of the accident. The procedure starts at the station, where everyone gathers and collects the resources needed for the response; for a full-time crew, it takes approximately 90 seconds to prepare, while the part-time crew needs an additional five minutes (Räddningsverket 2003). However, this type of homogeneous planning of the Swedish FRS is about to change and some FRS have already implemented changes more tailored to the needs of its municipality.

Information on the changes that have occurred in the Swedish FRS during the last decade were collected from previous studies and through a survey that was sent out to fire managers in Sweden specifically for this study (see section 7). 


\subsection{Formalized cooperation}

Municipalities in Sweden, as in many other countries in recent decades, have struggled with rising service costs. Demographics as well as wage increases and demanding clients have affected the resources available for welfare services in general (Pierre 2011). This has consequently affected the resources available for the FRS, and as a consequence, several neighboring municipalities have merged into formalized cooperations; that is, the FRSs have joined together around common administration and management in a group-like structure. ${ }^{4}$ Most of these cooperations are concentrated in the larger cities and in areas with relatively high population density; the main goal of the cooperations has been to become more cost-efficient and gain economies of scale by allowing technical exchange and transfer of knowledge. Today more than 120 FRSs in different municipalities are part of a formalized cooperation; during the period studied in this paper (2009-2012), the number of municipalities that collaborate in formalized cooperations increased from approximately 97 to 120 .

The main reason for entering a cooperation is to benefit from economies of scale (eg. Honadle, 1984). However previous studies also emphasizes that transaction costs are likely to occur, e.g. costs related to planning, adapting and monitoring the cooperation (eg. Bel and Warner, 2014). The question is therefore whether the potential efficiency wins will compensate for expenses related to transactions costs. Previous research on the relationship between cooperation between municipalities and costs is scant and contradictory (ibid), and to our knowledge there have not been any specific studies on the effects from cooperation on cost-efficiency in the FRS area. Most previous studies have looked at waste collection, this study therefore contributes to the literature by analyzing a different public sector.

\subsection{Collaborations with public, private actors and non-profit organizations}

Efficiency-enhancing activities in the Swedish FRS are generally related to reductions in response time since the outcome of an incident correlates strongly with the response time (Juås and Mattsson 1997). However, reducing response time with existing resources in a cost-efficient way is not easy. It requires many firefighting resources to be located at accessible places in communities so as to achieve good area coverage. One suggestion for reducing response time is therefore to increase collaboration with other actors. (Weinholt and Andersson Granberg 2013, Pilemalm et.al. 2013, Mojir and Pilemalm 2013). For instance, some FRSs have started to collaborate with home care personnel or security officers who help them respond to alarms in order to decrease response time. These collaborations are still quite rare but during the study period (2009-2012) the number of municipalites engaged in these kinds of collaborations increased from 11 to 30. Studies on whether collaborations with other public sectors, the private sector or non-profit sectors actually leads to increased cost-efficiency are however rare and shows different results (Andrews and Entwistle, 2010).

\footnotetext{
${ }^{4}$ There are also examples of non-formalized cooperations taking place. Such cooperations might also have an effect on efficiency but it is hard to identify them and they might be loose in structure and they are therefore not included in this study.
} 


\subsection{Changes in rescue teams}

Another initiative for reducing response time has been to start using smaller units in rescue operations. In some of the municipalities that are using part-time firefighters, the FRSs have introduced the concept of a first response person (FRP). ${ }^{5}$ This initiative means that the unit leader, instead of going to the station on receiving the alarm, goes directly to the accident personally to break or mitigate the development of the situation at an early stage while waiting for the rest of the rescue team. In 2009, approximately 35 municipalities introduced FRP, and by 2012 more than 95 municipalities had implemented this new way of working. The effects on response time of using FRP were evaluated in a Swedish case study; it was concluded that this new concept saved valuable response time and was profitable for society from a cost-benefit perspective (Lång 2012). However its effects on costefficiency has not been studied before.

\subsection{An increased number of tasks}

The number of tasks performed by the FRS has also increased. For example, the FRS collaborates with the ambulance services to a larger extent today. This initiative means that the FRS receives and responds to alarms intended for ambulance services in order to provide the basic rescue skills in lifethreatening incidents while waiting for the ambulance (WfA). ${ }^{6}$ Between 2009 and 2012, the number of municipalities that had established this kind of agreement between the FRS and the ambulance service increased from 184 to 261. Studies have shown that this initiative has saved several lives when doing early defibrillation in cardiac arrests and that this is profitable from a cost-benefit perspective (Sund et al. 2012). So far, no studies have evaluated whether this change has increased efficiency in the FRS.

\section{A Production and Cost Model for Fire and Rescue Services}

Efficiency is generally a question of using few inputs (resources) to produce outputs (services). To evaluate efficiency, one can use a cost function, which by definition shows the smallest possible cost of providing service at different output levels (Bogetoft and Otto 2010). Estimating the cost function is in some cases a straightforward process, e.g., labor and some tools and/or machinery (capital) are used in the production of a specific good having well-defined properties (Coelli et al. 2005). In other cases, it is not as easy to define what is actually produced. This problem is most pronounced in the production of services (Jansson 2013) and was early discussed in Bradford et al. (1969) where a conceptual framework was developed for defining public output. In that work, a distinction was made between direct outputs (the services directly produced) and the outcome of interest to citizens. A twostage public production process was developed, and this framework has been further elaborated and applied to the case of the FRS by Duncombe (1992), Duncombe and Yinger (1993), Duncombe and Brudney (1995) and Donahue (2004). Following these studies, the production of public services is

\footnotetext{
${ }^{5}$ Första insats person, FiP, in Swedish

${ }^{6}$ I Väntan På Ambulans, IVPA, in Swedish
} 
viewed as having two stages. The first stage is not different from that of a private firm where inputs are transformed to outputs and agencies choose and deploy several combinations of inputs such as labor $(L)$ and capital $(K)$ that enable the production of governmental outputs, $G$, according to

$G=f(L, K)$.

Assuming cost minimization, the total cost function (TC) can be described as $T C=c(W, G)$

As previously mentioned, the cost function shows the minimum cost of producing a given quantity of outputs from the available inputs. Costs are therefore expressed as a function (c) of output levels and factor prices, where $\mathrm{W}$ is a vector of input prices and $G$ is the level of output (or a vector of output levels if a multiple output technology is described, as in the case of the FRS).

Different levels of capital and labor can produce a certain level of fire inspections or turnouts. However, citizens will not care about the number of fire inspections or turnouts produced per se; instead, they will be concerned about how the level of safety is affected by these outputs. Hence, the output in Equation 1 is only an intermediate output. The second stage of the production process, therefore, needs to consider the transformation of these intermediate outputs into the outputs of importance to citizens, $S$, according to

$S=h(G, N, E)$,

where Equation 3 is a function of the intermediate output $(G)$, the population $(N)$ served by the FRS as well as the environmental conditions and socioeconomic variables $(E)$ that affect the service delivery. Solving for $G$, this implies the following second stage of the production function

$G=h^{-1}(S, N, E)$

Substituting (4) into (2) results in a second stage cost function according to

$T C=c\left(h^{-1}(S, N, E), W\right)$.

This is the model developed by Bradford et al., which assumes that the environmental or socioeconomic factors $(E)$ only affect the production in the second stage (Bradford et al. (1969). However, other studies showed that environmental factors are likely to affect factor substitution of inputs and the production of outputs even at the first stage of production (Duncombe 1992, Duncombe 
and Yinger 1993, Duncombe and Brudney 1995). These environmental and socioeconomic factors $\left(E^{\prime}\right)$ were therefore incorporated into their cost model (see Equation 6). This model was further developed in Donahue (2004), where the effects of management behavior $(M)$ and organizational factors $(O)$ on cost efficiency in the FRS were analyzed, and it was found that a higher level of active management was associated with lower per capita costs. Hence, this could also be included in Equation 6 according to

$T C=c\left(h^{-1}(S, N, E), W, E^{\prime}, M, O\right)$.

\section{Introducing Inefficiency}

The cost function expressed in Equation 6 is deterministic and assumes that operations are performed in an efficient (cost-minimizing) manner. This is an unrealistic assumption, and we therefore introduce the concept of cost frontiers, which can be estimated with stochastic frontier analysis (SFA). Expressing costs in terms of a frontier allows for the possibility of inefficiency in the operations of individual decision-making units according to

$T C_{i} \geq c\left(S_{i}, N_{i}, E_{i}, W_{i}, M_{i}, O_{i}\right)$

where $T C_{i}$ is the total cost for decision-making unit (DMU) $i$, producing $S_{i}$, to a population $N_{i}$ with a socioeconomic profile of $E_{i}$ (including $E_{i}^{\prime}$ ), facing factor prices $W_{i}$, management behavior $M_{i}$ and organizational factors $O_{i}$. Introducing $d_{i}$ as a measure of the inefficiency of DMU $i$ and a random disturbance term $\varepsilon_{i}$ gives the following expression:

$T C_{i}=c\left(S_{i}, N_{i}, E_{i}, W_{i}, M_{i}, O_{i}\right)+d_{i}+\varepsilon_{i}$,

where $d_{i}$ is a non-negative random variable describing how far off a DMU $i$ is from producing a given level of output $\left(S_{i}\right)$ efficiently, taking into account factors outside of the DMU control (such as population, socioeconomic factors, and factor prices). The first part of the right-hand side of Equation 8 is the cost front, which is the lowest cost at which FRS $i$ can produce output $S_{i}$ given the context in which it operates $\left(N_{i}, E_{i}, W_{i}, M_{i}\right.$, and $\left.O_{i}\right)$.

Conceptually, when using SFA, we are measuring how far from the efficient cost frontier the different FRSs are located. As previously mentioned, when using SFA, one separates the inefficiency term $(d i)$ and the random error term $\left(\varepsilon_{i}\right)$. Figure 1 illustrates the principles underlying SFA when only one output is produced. 


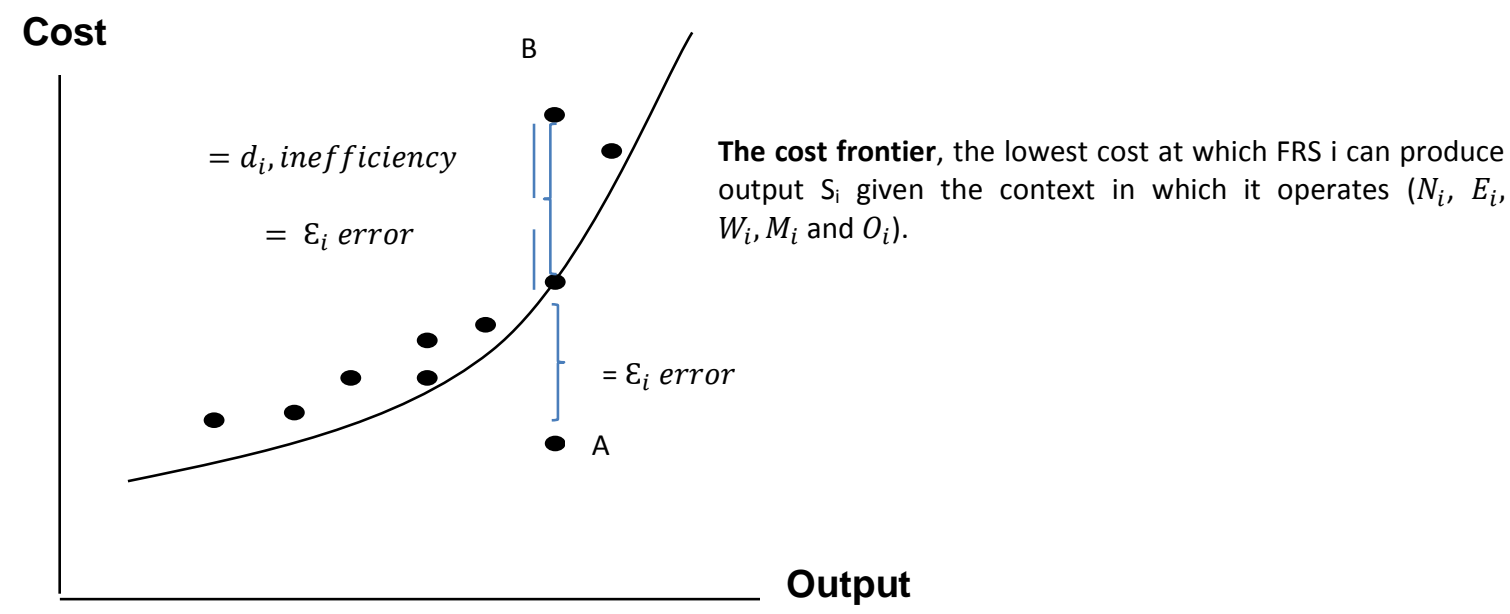

Figure 1. Illustration of the principles underlying SFA with a single output.

The method has two notable features: (1) it does not necessarily correspond to the "line of best fit" as would be the case in a simple regression model, and (2) the frontier does not necessarily pass through the observation that produces the lowest observed cost (e.g., observation A lying below the frontier). This is because the frontier is estimated after recognizing that some of the difference between observed cost and the level of cost predicted by the explanatory variables may be due to unexplainable random effects. For observations lying above the frontier (e.g., observation B), the higher cost level will be due both to inefficiency and a random error term. Cost efficiency (CE) is usually defined as

Cost efficiency $=\frac{\text { Minimum } \cos t}{\text { observered } \cos t-\varepsilon_{i}}$.

\section{Defining Inputs and Outputs in Fire and Rescue Services}

Before evaluating whether the organizational changes in FRS in Sweden have improved efficiency, we need to define inputs and outputs. Valuing the inputs is relatively straightforward and can be done by observing the wages of the firefighters, the costs for administration, technology or for the fire brigades, given that data for this are available. However, the outputs from fire suppression and fire preventive activities are more difficult to capture, as the output measure should represent the difference between what could have happened and what actually happened. The FRS produces multiple outputs including life savings, reduced property damage, preparedness, and a higher level of perceived safety. However, data on these outputs are not always available or even possible to collect, 
as acknowledged in previous studies where several proxies have been used to capture both intermediate and final outputs. As previously mentioned, there have been only a few efficiency studies of FRS (e.g. Jaldell 2002, Ahlbrandt 1973, Kristensen 1983, Bouckaert 1992, Choi 2005, Peng M et al. 2014). However, even though pure efficiency studies have not been performed on a large scale, some studies have tried to estimate the supply or the cost function in the FRS (e.g. Hirsch 1959, Southwick and Butler 1985, Coulter 1979). Table 2 presents the different proxies for outputs which have been used.

The first studies that tried to define outputs in the FRS were presented in Hirsch (1959) and Ahlbrandt (1973), where population, area, assessed property value, and density of dwelling units were used as proxies for outputs. It was argued that changes in output, holding quality constant, might involve simultaneous changes in the number of people, area, and structures protected. These measures, however, are not under the control of the FRS; therefore we argue that they should be seen as environmental factors.

It has also been argued that the numbers of fires and preventive activities are representative proxies for outputs (Bouckaert 1992). Many previous studies have also used the inverse of losses per fire as proxy for the final output (Hirsch 1959). However, in Jaldell (2002) it was argued that the response time, measured by the number of people reached in $\mathrm{x}$ minutes, and the total number of firefighters reaching the fire are more representative output measures since these are under the control of the FRS.

The output measure also needs to capture fire prevention activities. Ideally, the measure of prevention should be the number of fires or incidents prevented by having FRSs. Since this number is not possible to obtain, the actual number of fires could be used as proxy. Given the contextual factors, more fires occurring in an area should reflect the efforts put into prevention. In recognition of this, for instance, previous studies have used the number of fires per 1000 inhabitants (Coulter 1979), the inverse of the number of fires per inhabitants (Bouckaert 1992), or the inverse of fires per dollar of property value (Duncombe 1992, Duncombe and Yinger 1993, Duncombe and Brudney 1995).

As shown in Table 2, the most commonly used proxy is fire loss or property loss followed by fire deaths and total number of fires. ${ }^{7}$ In Sweden, however, data on fire loss or property loss are not available because insurance companies do not provide this information.

Table 2 also shows that there has been no dramatic development or discussion concluding which output measures best capture the FRS output, even though researchers have addressed this issue for almost half a century. One of the last found studies that evaluated efficiency in the FRS used direct fire losses and fire deaths as the only output measures for the FRS (Peng et al. 2014).

Based on the previous discussion, the present study uses number of turnouts, number of fires per person, number of workers for preventive work, and response time as output measures $\left(S_{i}\right)$ for each DMU. By using these proxies, we do not argue that we know exactly which variables are the most

\footnotetext{
${ }^{7}$ Some of the studies presented in table 2 used DEA when studying efficiency.
} 
important. Our argument, as also stated in Choi (2005), is minimalist and we argue that we have found general agreement from previous studies that those used in this analysis are not unimportant when examining the efficiency of FRS.

\section{Table·2.Examples·of-proxies·for-output· used-in-previous-studiesश}

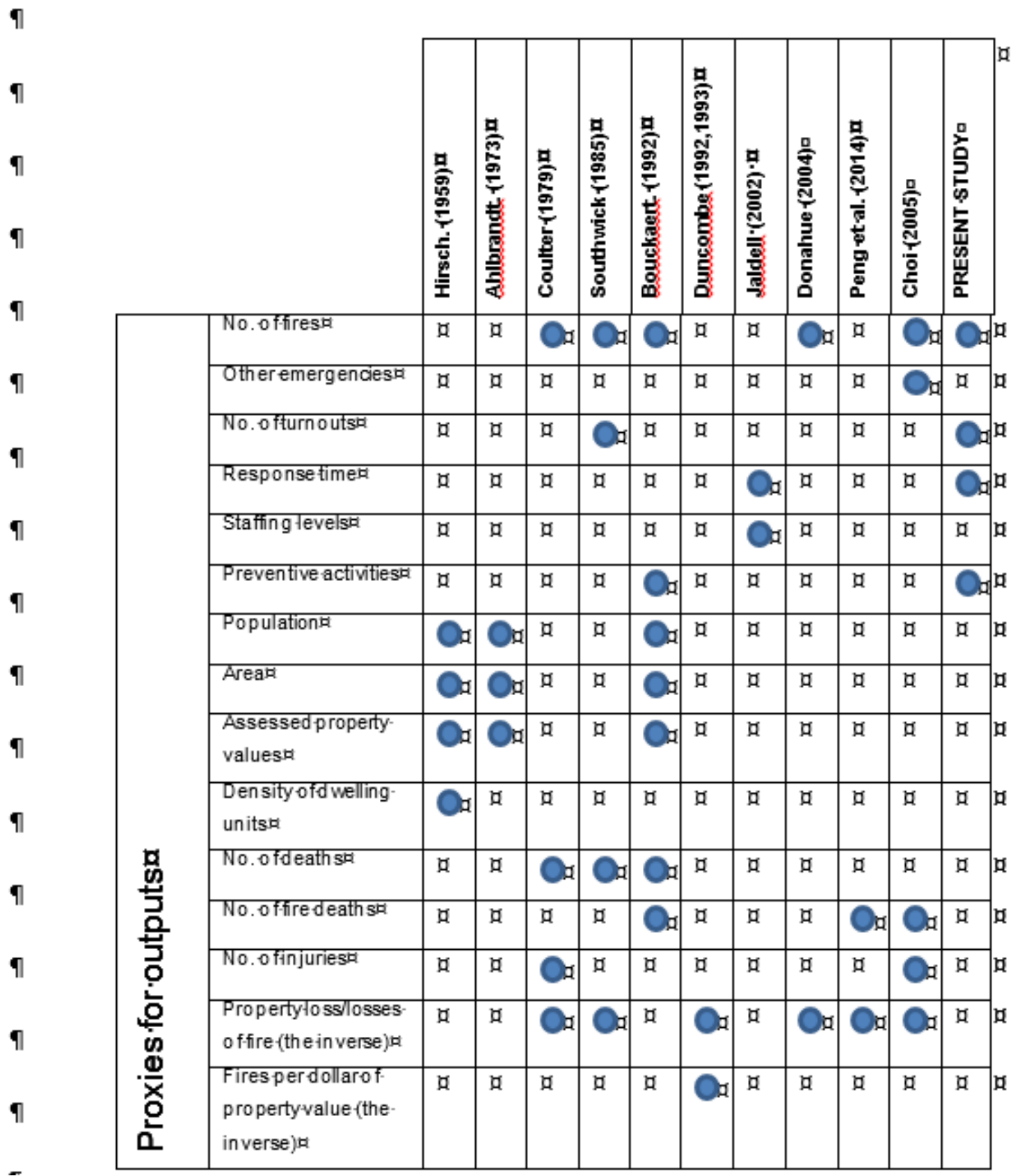

In this study, the actual number of turnouts is assumed to be a proxy for lives and property values saved in case of the occurrence of incidents. The number of turnouts, however, could be a contradictory measure since a high number of turnouts could imply that the FRS does not perform well in their preventive work. We therefore also included the number of fires per person as a proxy for prevention, as was also done in Bouckaert (1992), Duncombe (1992), Duncombe and Yinger (1993), Duncombe and Brudney (1995) as well as in Coulter (1979). From a statistical viewpoint, number of turnouts and fires are supposedly highly correlated, which could make it hard to identify separate 
effects on costs from them. However, using them together might add information on the variation in costs, since it is unlikely that the correlation between them is $100 \%$. Therefore, we consider it useful to try including them both. We also included the number of people employed specifically for preventive work as part of our proxies for preventive output; this proxy has not been used in any previous studies.

The number of turnouts is assumed to increase costs, but the number of fires per person should be related to lower $\operatorname{costs}^{8}$ since a high number of fires (all else being equal) would imply lower expenditure of resources on prevention. ${ }^{9} \mathrm{We}$ also included response time as an output measure because the level of saved lives and property values is strongly affected by how fast the FRS can reach the incident site. This proxy was also used as many of the implemented changes were introduced with the goal of improving response time. However, the faster you are able to reach the incident site, the higher are the probable costs for the FRS because the possibility of reaching the incident scene fast will be affected by having many resources located at accessible places to achieve good coverage.

Population is rather self-explanatory, a larger population requires more resources being spent on the FRS for a given level of quality. Average income in the municipality is used as a socioeconomic variable. Previous studies (e.g. Jennings 1999, 2013) have shown that the risk of fires occurring is higher in low income areas. Assessed property values are also included as a socioeconomic variable, this is assumed to capture the values protected by the FRS. This variable implies that the higher the value of assessed real estates, the higher the expected cost of a fire would be and it might also imply a larger number of houses in a given area. ${ }^{10}$ Therefore, area is also included as a socioeconomic variable and it is also plausible to assume that the size of the area in which a population is spread affects the costs, for actual turnouts as well as preventive work. Together with wages for firefighters in different municipalities (average wage in the municipality) and the cost of providing capital, these variables are assumed to affect the minimum cost level. For this study, data on capital costs in different municipalities were not available; the cost of capital is defined as the interest rate of ten-year government bonds. This is a simplification in our model but this proxy should represent, at least to some extent, the cost of capital in the public sector. ${ }^{11}$ The variables used to determine the frontier and their expected effect on costs are shown in Table $3 . \quad$ Variables representing management behavior or organizational factors are not included in our model. This is not because we do not consider them to affect efficiency; on the contrary, given that other factors have been accounted for, observed differences in efficiency should be caused by differences in management behavior or organizational factors. This study, however, cannot conclude exactly which factors within management behavior or which organizational factors affect inefficiency as we only chose to test specific changes in FRSs in Sweden during the last decade. For instance, our conclusions will not further explain the extent to which leadership is participatory or differences occurring in organizational structure, except the ones we test for.

\footnotetext{
${ }^{8}$ This, of course, refers to the costs incurred to the FRS and not to cost for society as a whole.

${ }^{9}$ See Bouckaert (1992), Duncombe (1992), Duncombe and Yinger (1993), Duncombe and Brudney (1995) for more on the topic.

1010 That beeing said, high value properties are often better protected against fire hazardz and therefore the expected effect of this variable is uncertain.

${ }^{11}$ This variable will vary over time but not between municipalities which of course is a simplification, but this is only a problem for the current analysis if this variation follows the variation in some other variable affecting costs.
} 
Table 3. Variables affecting the cost frontier.

\begin{tabular}{lll}
\hline Variable & Variable used in this study & Expected effect on costs \\
\hline Output (S) & Number of turnouts (Q) & Increasing costs \\
Output (S) & Nr of fires per person (F) & Decreasing costs \\
Output (S) & Nr of people employed for preventive work (P) & Increasing costs \\
Output (S) & Response time (T) & Increasing costs \\
Population (N) & Population (N) & Increasing costs \\
Environmental factor (E) & Income (Y) & Increasing costs \\
Environmental factor (E) & Assessed values for real estates (R) & Ambiguous \\
Environmental factor (E) & Area (A) & Increasing costs \\
Costs for input (W) & Wage of firefighters (W1) & Increasing costs \\
Costs for input (W) & Cost of capital (W2) & Increasing costs \\
\hline
\end{tabular}

\section{Organizational Changes and Expected Effects}

As mentioned in section 2 of this paper, Swedish municipalities have considerable freedom in how to organize and operate FRS. It is therefore natural to consider each municipality as a decision-making unit (DMU). This is the case also for municipalities taking part in formalized cooperations because they still retain a large degree of independence in planning of operations within their municipality. In addition, the decision whether or not to participate in such a cooperation is in itself a potentially important managerial decision left to the municipality. It is therefore natural to perform the analysis using data on a municipal level.

However, as mentioned earlier, each DMU is not necessarily efficient, i.e. producing at the lowest cost possible. As the organizational changes were introduced with the explicit or implicit goal of improving efficiency, the model tests whether and how efficiency has been affected by the changes (see table 4).

Table 4. Variables affecting inefficiency (deviation from frontier).

\begin{tabular}{ll}
\hline Variable & Expected effect on inefficiency \\
\hline Formalized cooperation (FC) & expected to decrease inefficiency \\
Cooperation with other actors (CoA) & expected to decrease inefficiency \\
First response person (FRP) & expected to decrease inefficiency \\
Waiting for ambulance (WfA) & ambiguous \\
Part-time firefighters (PtFF) & ambiguous \\
\hline
\end{tabular}

As mentioned before, an increasing number of municipalities are nowadays collaborating in formalized cooperations (FC). The effect on efficiency is tested by including a dummy variable, taking the value 1 if the municipality is part of a formalized cooperation and 0 otherwise. This is assumed to 
decrease the inefficiency term $\left(d_{i}\right)^{12}$ since the FRS who are collaborating in cooperations do this in order to increases economies of scale.

The model also includes a dummy variable describing whether or not the FRS in the municipality is engaging in cooperation with other actors (CoA). Previous studies suggests that this has effects on service delivery, however whether it has positive effects on inefficiency has not thoroughly been investigated before. Although the hypothesis is that this will decrease the inefficiency $\left(d_{i}\right)$.

The introduction of first response person (FRP) is supposed to increase efficiency since the unit leader now can perform some tasks at an earlier stage. If nothing else, the leader should be able to assess the situation and reduce response time before the team arrives and therefore be able to better plan the rest of the operation. The effects of FRP on efficiency are also tested by including a dummy variable assumed to affect the inefficiency term $\left(d_{i}\right)$.

The model also tests whether the collaboration with the ambulance service (WfA) has affected inefficiency. The effects of this change could go both ways: if there are economies of scale in FRS production, an increase in turnouts might be reflected as a positive effect on inefficiency while it could also be that the FRS will experience higher costs due to this change, and in that way cancel out the higher degree of activity. This is also assumed to affect the inefficiency $\left(d_{i}\right)$.

The effect on efficiency of the widespread use of part-time firefighters (PtFF) is tested. This is not something new in the FRS but in the wake of increased demands on public funds, the use of part-time personnel having other jobs makes it possible for small municipalities to maintain a larger personnel force. At the same time, compared to full-time firefighters, response times are higher, and it is most likely harder to maintain skills and experience. In fact, full time- and part time firefighters can be seen as different categories of labor and the optimal mix of them probably differs between municipalities. Inefficiency should therefore arise only if the proportion of part time firefighters differs from the optimal level. It would therefore be better to include a variable showing the deviation from the optimal level but since this is not possible, the actual level is used as a proxy. Also some of the above mentioned changes (e.g. FRP) have only been introduced in FRSs having part-time firefighters why this variable might be interesting to investigate further. The expected effect of using part-time personnel on efficiency is however ambiguous. It might increase efficiency or it might reduce it. The variable is measured by the proportion of the hours of employed labor that comes from part-time personnel.

In empirical applications, one must specify the functional form of Equation 8 before estimation. Several functional forms have been applied in empirical studies of efficiency; Coelli et al. (2005) list several functional forms often used. The two most common are the Cobb-Douglas function and the

\footnotetext{
12 As pointed out, for example, by Coelli et al. (2005), it might be difficult to determine which variables are part of determining the frontier and which affect the inefficiency of operations. Therefore, the variables presented in this section as affecting inefficiency are also tested for inclusion in the frontier part of the model, one-by-one and as a group.
} 
translog function. ${ }^{13}$ The former can be seen as a first-order approximation of an arbitrary function at a specific point and the latter as a second-order approximation. The translog function is therefore more flexible and might be preferable on that basis (Chambers 1988). However, in many cases, using a translog function might cause difficulties as the number of parameters to be estimated rises dramatically if the study includes more than a few explanatory variables; problems with multicollinearity are common (Coelli et al. 2005). We therefore adopt an estimation strategy in which we start with a Cobb-Douglas function and then successively introduce second-order and interaction terms. ${ }^{14}$ Following Coelli et al. (2005), the starting point of the analysis is a Cobb-Douglas specification of Equation 8 in which the inefficiency term $\left(d_{i} \sim N^{+}\left(m_{i, t}, \sigma^{2}\right)\right)$ and the error term $\left(\varepsilon_{i} \sim N\left(0, \sigma_{\varepsilon}^{2}\right)\right)$ are added to the Cobb-Douglas cost function after it has been linearized. The variables included in the frontier part of the model are presented in Table 3, and the variables included in the truncation point of the inefficiency term $\left(m_{i}\right)$ are presented in Table 4. Defining $c_{i, t}$ as total costs divided by wage level for firefighters and $w_{i, t}$ as cost of capital divided by wage level for firefighters 15 in municipality $i$ time period $t$, the starting model is therefore:

$$
\begin{gathered}
\ln c_{i, t}=\beta_{0}+\beta_{1} \ln w_{i, t}+\beta_{2} \ln N_{i, t}+\beta_{3} \ln A_{i, t}+\beta_{4} \ln Q_{i, t}+\beta_{5} P_{i, t}+\beta_{6} R_{i, t}+\beta_{7} Y_{i, t}+\beta_{8} T_{i, t}+\beta_{9} F_{i, t} \\
+d_{i, t}+\varepsilon_{i, t}
\end{gathered}
$$

and

$$
m_{i, t}=+\alpha_{1} F R P_{i, t}+\alpha_{2} F C_{i, t}+\alpha_{3} \operatorname{CoA}_{i, t}+\alpha_{4} W f a_{i, t}+\alpha_{5} P t F F_{i, t}
$$

\section{Data Collection}

To obtain data on municipalities that have begun a collaboration with public and private actors, engaged in formalized cooperation, and started using FRP and WfA, a questionnaire was distributed to all the fire managers in Sweden ( $=290)$. The questionnaire comprised "yes/no" questions asking the fire managers to specify whether they had implemented such changes and, if so, which year the changes were implemented. The questionnaire was e-mailed to each of the fire managers, who were offered two alternatives to respond: either through a form or through a survey web link. In total, 221 of

\footnotetext{
${ }^{13}$ In general terms, the Cobb-Douglas function can be expressed as:$$
y=\beta_{0} \prod_{n=1}^{N} x_{n}^{\beta_{n}}
$$$$
\text { and the translog function as: }
$$$$
y=\exp \left(\beta_{0}+\sum_{n=1}^{N} \beta_{n} \ln x_{n}+\frac{1}{2} \sum_{n=1}^{N} \sum_{m=1}^{N} \beta_{n m} \ln x_{n} \ln x_{m}\right)
$$$$
{ }^{14} \text { A linear model ( } y=\beta_{0} \sum_{n=1}^{N} \beta_{n} x_{n} \text { ) was also tried, but in that case none of the variables was found to be statistically significant. }
$$$$
{ }^{15} \text { Cost of capital is divided by wage in order to ensure homogeneity in prices (i.e. if all prices increase equally it }
$$
does not affect c) see e.g. Coelli et.al (2005) for examples.
} 
the 290 municipalities responded to the questionnaire. Two reminding e-mails were sent to the participants and some were contacted directly through phone calls.

Municipal data on population, area, per capita costs, income levels, number of turnouts, response times, fires, and number of employees as well as the proportion of full-time, part-time, and preventive workers were provided by the Swedish Civil Contingency Agency $(M S B)$. Data on wages for the firefighters and assessed values for real estates were obtained from Statistics Sweden $(S C B) .{ }^{16}$ Capital costs were defined as the interest rate of ten-year government bonds; these data were provided by the Swedish Central Bank (Riksbanken). Due to missing data, only 205 of the municipalities could be included in the statistical analysis, making the total number of observations 820 . The study used annual data from 2009 to 2012, the reason for the relatively short period being that data on certain variables such as response time were not available for longer periods. Possible consequences will be discussed later.

\section{Results and Discussion}

The model was estimated by maximum likelihood, using the statistical software LIMDEP (see Greene 2000) for a general discussion of maximum likelihood estimation and Coelli et al. (2005) for a discussion of maximum likelihood estimation of stochastic frontier models). Variables not found to be statistically significant were eliminated one at a time and retested for entry into the model after each new elimination. The final result of the estimation is:

Frontier: ${ }^{1718}$

$$
\begin{aligned}
\ln c_{i, t}= & -2.18+0.15 \ln w_{i, t}+0.78 \ln N_{i, t}+0.18 \ln A_{i, t}+0.14 \ln Q_{i, t}+0.02 R_{i, t}-0.04 T_{i, t}-0.06 F_{i, t} \\
& (0.34)^{* * *}(0.008)^{* * *}(0.05)^{* * *} \quad(0.18)^{* * *}(0.05)^{* * *}(0.01)^{*} \quad(0.02)^{*} \quad(0.03)^{*}
\end{aligned}
$$

Inefficiency:

$$
\begin{aligned}
m_{i, t}= & 0.29 \operatorname{Co} A_{i, t} \\
& (0.06)^{* * *}
\end{aligned}
$$

\footnotetext{
${ }^{16}$ www.scb.se

${ }^{17}$ Standard deviation in parentheses; $* * *$ significance level at $1 \%$ level, $* *$ significance level at $5 \%$ level, $*$ significance level at $10 \%$ level.

${ }^{18}$ It is worth noting that no second-order or interaction terms tested were found significant. Income was not significant either, which might be due to correlation with the property value variable, i.e., they might capture the same effect. Relative to most countries, Sweden exhibits small variations in income which might also explain why it is not significant. The number of people employed exclusively for preventive work was not found significant either.
} 


\subsection{The frontier}

In general, the effects in the frontier part of the model can be interpreted as elasticities, i.e., as the percentage change in the dependent variable due to a $1 \%$ change in the explanatory variable. A $1 \%$ increase in population $(N)$ therefore raises the expected cost of FRS by $0.78 \%$, while a $1 \%$ increase in area served $(A)$ is expected to increase costs by $0.18 \%$. Increased number of turnouts $(Q)$ increases costs by $0.14 \%$, as was expected. Higher property values $(R)$ in a municipality also increases expected costs by $0.02 \%$, which is in line with the expectation that it should reflect a higher level of risk. Response time $(T)$ is found to have a statistically significant effect on costs and has a negative sign. This is in line with expectations because allowing for longer response time results in lower costs, i.e., reducing response time is expected to cost money, and the elasticity is found to be 0.04 .

The number of fires in a municipality is found to have a negative impact on costs: as the number of fires increases by one percent, the costs decrease by $0.06 \%$. At first glance, this might appear strange but it should be kept in mind that this variable is thought to reflect preventive work performed by the FRS. Therefore, the occurrence of more fires in an area (keeping all other variables constant) reflects less effort being put into preventive work and is found to result in lower expected costs. The findings from the cost frontier are consistent with the results presented in previous studies (Jaldell 2002, Ahlbrandt 1973, Kristensen 1983, Bouckaert 1992, Choi 2005, Peng et al. 2014, Duncombe 1992, Duncombe and Yinger 1993, Duncombe and Brudney 1995, Donahue 2004, Hirsch 1959, Southwick and Butler 1985, Coulter 1979), where a higher level of fire suppression and fire prevention activities is related to higher costs.

\subsection{Inefficiency}

Cost efficiency $\left(\mathrm{CE}_{\mathrm{i}, \mathrm{t}}\right)$ of municipality $i$, period $t$, is defined as the ratio of minimum cost to observed cost (e.g. Coelli et.al. 2005, Bogetoft and Otto, 2010) In terms of Equation 8, this is:

$$
C E_{i, t}=\frac{C\left(S_{i, t}, N_{i, t}, E_{i, t}, W_{i, t}, E_{i}^{\prime}, M_{i}, O_{i}\right)}{C\left(S_{i, t}, N_{i, t}, E_{i, t}, W_{i, t}, E_{i}^{\prime}, M_{i}, O_{i}\right)+d_{i, t}}
$$

Industry efficiency is usually defined as the average efficiency (Coelli et al. 2005). In this case, the industry efficiency was found to be 0.72 , or $72 \%$. Appendix 1 shows the efficiency level in each of the municipalities included in this study.

Inefficiencies vary among DMUs but, due to the short time period, the only source of variation over time being modeled is the effect of having started collaborating with private, public or non-profit actors during the observed period. Hence, the effects on the inefficiency term $\left(d_{i, t}\right)$ were not as expected. Most of the variables tested for inclusion in the model (see Table 4) were not found significant. Our conclusion from this is that the organizational changes tested for has not had any measurable effects on efficiency. As pointed out, for example, by Coelli et al. (2005), it might be 
difficult to determine which variables are part of determining the frontier and which affect the inefficiency of operations. Therefore, the variables presented in Table 3 were also tested for inclusion in the frontier part of the model, one-by-one and as a group. None was found significant.

Cooperation with other actors $(\mathrm{CoA})$ was found significant, but unexpectedly it had a positive sign. Municipalities employing cooperation schemes were therefore on average found to be less efficient than other municipalities. A possible explanation for this finding is that some cooperations were implemented by municipalities that for some other reason were less efficient than others or that the positive effects cannot be seen yet due to them being only recently started. This result could also mean that potential gains are counterbalanced by transaction costs, i.e. a need to expend more time and resources building relationships with these new actors (Bel and Warner 2014). Previous studies highlights that collaboration might yield positive outcomes in terms of increased efficiency, however small municipalities are more likely to gain economies of scale than large ones (ibid). In this study we have only tested for collaboration and we have not specified what type of collaboration that the municipalities are engaged in (public, private or non-profit). Previous studies have indicated that this might have effect on whether the collaboration will lead to increased cost-efficiency (Andrews and Entwistle 2010). A suggestion for future research is therefore to build on the work presented here and in Andrews and Entwistle (2010) and analyze how collaboration with different types of organizations (public, private or non-profit) affects efficiency levels in the FRS.

It was also hypothesized that formalized cooperation between FRSs in neighboring municipalities would have effects on efficiency. This variable however was not found to be significant, even though the main goal of the cooperation is to increase economies of scale and produce more with available resources. One explanation could be that the gains is outweighed by transactions costs for managing these kinds of cooperations, which have been shown also for other sectors (e.g. Dollery and Akimov 2014). Some Swedish studies have also implied that the implementing process of a formalized cooperation takes time and that it is difficult to bring together FRSs who for a long time have been used to doing things in their own way (Stenberg 2012;2013). Since the investigated time period is relatively short there might be positive effects occurring in the long run that was not captured in this study.

Another variable that was believed to have effects on efficiency was the supportive role to the ambulance service (WfA). WfA, however, did not have significant effects; one explanation could be that as the turnouts increase, the costs also increase, with the possible outcome that these effects cancel each other out.

Introducing FRP, using smaller units in rescue operations, was also believed to have positive effects on efficiency. However, this policy change did not have any measurable effect on efficiency when controlling for context and production level. Another variable thought to affect efficiency was the use of part-time firefighters. However, this variable was not found significant, i.e., it had no 
measurable effect on efficiency when controlling for other variables. A possible conclusion from this is that FRS in Sweden are actually using an efficient mixture of full- and part-time labor.

Jaldell (2002) concluded that industry efficiency in Swedish SFS was low, about 70\%. In this study, we found an overall efficiency of $72 \%$. The overall picture is therefore that there was no evidence to be found of improved efficiency in the FRS. This was further supported by the lack of positive effects on efficiency from the policy variables examined in the study. One should however, according to Kumbhakar and Lovell Knox (2000), be careful when comparing results from efficiency studies using production functions (as was the case in Jaldell 2002) with those using cost functions as has been done in this study. It should be emphasized that this study is not a replication of the studies presented in Jaldell (2002). Nevertheless, there is a consistency in the results indicating that industry efficiency in the FRS in Sweden still appears to be around 70\%. However, behind the overall industry average, the efficiency of the 205 individual municipalities included in the study exhibits a great deal of variation. Nine of the municipalities have an efficiency level below $40 \%$ while 31 have efficiency levels of $90 \%$ or higher (see Appendix 1).

It has also been acknowledged that even though measuring efficiency in the public sector, using formalized tools such as SFA or DEA ${ }^{19}$, has become popular both in academia and among policy makers themselves, there are still limits of analysis that need to be considered (Smith and Street 2005). This is even more apparent when analyzing industries where the production process is complex, as in the case of the FRS. The FRS is a multiple output producer and among other things the output estimates should try to capture the level of perceived safety in a society. As has been highlighted in this study, modeling the production process is not a straightforward matter and, even though research involving defining output measure for the FRS has been addressed since the 1960s, there is still little consensus on what measures or proxies should be used to best capture the process. Another issue is that the efficiency of the FRS is dependent on many environmental factors that lie outside organizational control. It is difficult to find a model that guarantees that all the environmental factors (differences in the characteristics of citizens being served, geography, climate, culture, quality of resources being used, or different organizational priorities, to name a few) are taken into account. First, one needs to define all the potential differences that might explain differences among the municipalities; and secondly, one must acquire access to all the data for these variables.

Another difficulty is the treatment of dynamic effects. Most organizations are influenced by their historical context and are to some extent dependent on previous investments. Contemporary inputs are to some extent also invested for future outputs. In this case, it could be that some municipalities showing low efficiency have been investing in preventive efforts or new technology that will give rise to positive effects in the future. This is unfortunately not captured in this model. Our model also

\footnotetext{
${ }^{19}$ Data envelopment analysis, another common method used when analyzing efficiency. To read more on DEA see e.g. Bogetoft and Otto (2010).
} 
considers a relatively short time period; by prolonging the period of study, it might be possible to capture more causes of relative efficiency.

This being said, we believe that the combination of variables used in this study captures many aspects of FRS production. We also believe that this study might influence more research on this topic since there is still few studies that have evaluated the actual effects on cost efficiency in the public sector from implementing new initiatives that involves collaborative practices. In this paper we find that cost efficiency has not been affected by the implemented changes. This corresponds to previous findings in studies from other sectors. However, the opposite effect (i.e. improvements in efficiency) has also been found in some studies. For natural reasons it is difficult, if not impossible, to draw generalizable conclusions on the effects on efficiency from cooperation and collaboration in the public sector. This is indeed important given the ongoing debates in metropolitan service delivery and given the fact that these initiatives are seen as alternative tools for increasing efficiency. We therefore welcome more research on this particular matter in order to identify under which circumstances and in which policy areas such initiatives will result in a favorable outcome.

\section{Conclusion}

Previous studies have shown low efficiency in the Swedish FRS but the recent harsher fiscal environment has affected the amount of municipal resources available for FRS activities and has thus forced the FRS to strive for higher flexibility and efficiency. The central interest of this study has been to examine whether cost efficiency of FRSs in Swedish municipalities has been affected by the organizational changes implemented in a large number of FRSs over the last decade. The policy changes of interest in this study have been an increased number of formalized cooperations between FRSs, the increased number of collaborations with other actors, the use of smaller units in rescue operations, and a more supportive role to the ambulance service.

The conclusion is that none of these changes can be seen to have increased efficiency. This is further supported by the finding of an average efficiency level of $72 \%$, which is in line with findings in older studies of efficiency in Swedish FRS (Jaldell 2002).

This might be disheartening from a policy perspective but the main message is that introducing these changes will not result in any quick fix in terms of cost efficiency. Previous studies, in different sectors, show similar results and argue that transaction costs from these changes might outweigh the potential efficiency gains (Bel and Warner 2014). One recommendation is therefore to further investigate why these potentially efficiency-increasing initiatives have not yet given the expected results by doing in depth case studies or by studying if the same results can be shown when analyzing other sectors.

Another recommendation is to look more closely at the workings of individual municipalities and their FRSs. Of the 205 municipal FRSs included in the study, 9 were found to have an efficiency level below $40 \%$ while 31 were found to have efficiency levels of $90 \%$ or higher. Further in-depth 
comparisons between the most and least efficient municipalities might shed further light on the causes of relative efficiency. For instance it would be interesting to build on the work performed in Donahue (2004), and investigate more deeply how management behavior and organizational factors affect cost efficiency within the FRS to determine the success factors in the most efficient municipalities.

An important methodological aspect of this study has been the specification of a model capable of capturing the many aspects of FRS output and the context in which the FRSs are working. By combining output measures used in previous studies of FRS production and costs (number of turnouts, fires per person, number of people employed for preventive work, and response time), we believe that the model used in this study is able to capture the production complexities in the FRS. This might be useful in other studies of the FRS, when analyzing other sectors or in future studies performed to follow up this one. However, as has been acknowledged here and by previous researchers, there is still a need for more research on how to define representative output measures in the FRS, and the need is probably even bigger today in a time when the FRS, at least in Sweden, is an organization in change. Much of the work performed by the FRS nowadays is focused on improving safety in society as a whole and not only on improving fire safety. It would therefore be of great usage to develop key performance indicators adapted to the organization as it looks today.

Also there exist studies on what factors that increases fire risk (e.g. Jennings 1999, 2013), but as the FRS are engaging in more types of incident types and extending their mission to more preventive activities the discussion regarding which socioeconomic and environmental factors that affect the ability to produce outputs efficiently needs to be updated.

\section{References}

Ahlbrandt, R.J. (1973) Efficiency in the provision of fire services. Public Choice 16, pp 1-15

Andrews, R., Entwistle, T. (2010) Does cross-sectoral partnership deliver? An empirical exploration of public service effectiveness, efficiency and equity. Journal of Public Administration Research and Theory

Bel, G., Warner, M.E. (2014) Inter-municipal cooperation and costs: expecations and evidence. Forthcoming Public Administration

Bogetoft, P., Otto, L. (2010). Benchmarking with DEA, SFA, and R. New York, Springer.

Bouckaert, G. (1992) Productivity analysis in the public sector: the case of the fire service. International Review of Administrative Sciences, 58, pp 175-200

Bradford, D.F., Malt, R.A., Oates, W.E. (1969) The rising cost of local public services: some evidence and reflections. National Tax Journal, 22:2, pp 185-202 
Chambers RG (1988) Applied production analysis: a dual approach. Cambridge University Press, Cambridge

Choi, S.O. (2005) Relative efficiency of fire and emergency services in Florida: an application and test of data envelopment analysis. Int. J. Emergency Management, 2, pp 218-230

Coelli, T.J., Prasada Rao, D.S., O’Donnell, C.J., Battese, G.E. (2005) An introduction to efficiency and productivity analysis. Springer, New York

Coulter, P.B. (1979) Organizational effectiveness in the public sector: the example of municipal fire protection. Administrative Science Quarterly, 24:1, pp 65-81

Dollery, B., Akimov, A. (2014) Are shared services a panacea for Australian local government? A critical note on Australian and International Empirical Evidence. International Review of Public Administration, 12:2, pp 89-102

Donahue, A.K. (2004) The influence of management on the cost of fire protection. Journal of Policy Analysis and Management, 23:1, pp71-92

Duncombe, W.D. (1992) Costs and factor substitution in the provision of local fire services. The Review of Economics and Statistics, pp 180-184

Duncombe, W.D., Brudney, J.L. (1995) The optimal mix of volunteer and paid staff in local governments: an application to municipal fire departments. Public Finance Review, 23, pp 356-384

Duncombe, W.D., Yinger, J. (1993) An analysis of returns to scale in public production, with an application to fire protection. Journal of Public Economics, 52, pp 49-72

Greene, W. (2000) Econometric analysis, 4th edn. Prentice Hall, New York

Hirsch, W.Z. (1959) Expenditure implications of metropolitan growth and consolidation. The Review of Economics and Statistics, 41:3, pp 232-241

Honadle, B.W. (1984) Alternative service delivery strategies and improvement of local government productivity. Public Productivity Review, 8:4, pp 301-313

Jaldell, H. (2002) Essays on the performance of fire and rescue services. Dissertation, Göteborgs Universitet

Jansson, J.O. (2013) The economics of services - microfoundations, development and policy. 2nd edn. Edward Elgar, Cheltenham UK

Jennings, C.R. (1999) Socioeconomic Characteristics and Their Relationship to Fire Incidence: A Review of the literature. Fire technology, 30:1, pp 7-29 
Jennings, C.R (2013) Social and economic characteristics as determinants of residential fire risk in urban neighborhoods: A review of the literature. Fire safety journal, 62, pp 13-19

Juås, B., Mattsson, B. (1997) The importance of the time factor in fire and rescue service operations. Accident Analysis and Prevention, 29:6, pp 849-857.

Kristensen, O. (1983) Public versus private provision of governmental services: the case of Danish Fire Protection Services. Urban Studies, 20, pp 1-9

Kumbhakar, S.C., Lovell Knox, C.A. (2000) Stochastic frontier analysis. Cambridge University Press, Cambridge

Lång, E. (2012) Är införande av förstainsatsperson samhälssekonomiskt lönsamts? En kostnadsnyttoanalys av FIP-verksamheten (Is introduction of first responders economically beneficial to society?: A cost-benefit analysis of the project of first responders in the municipality of Jönköping). Karlstad: Karlstad University.

Mojir, K.Y., Pilemalm, S. (2013) A framework for "new actors" in emergency response systems. Proceedings of the 2013 Information Systems for Crisis Response and Management (ISCRAM) Conference, Baden Baden, GE.

Peng, M. et al. (2014) Evaluation of fire protection performance of eight countries based on fire statistics: an application of data envelopment analysis. Fire Technology 50:349-361

Pierre, J. (2011) Cost-efficiency and public interest in inter-local partnerships. Urban Research \& Practice 4:1:13-22

Pilemalm, S., Stenberg R, Andersson Granberg T (2013) Emergency response in rural areas. International Journal for Information Systems for Crisis Response and Management, 5:2

Poister, T. (2008) Measuring performance in public and nonprofit organizations. Jossey-Bass, San Francisco

Rosenberg, T. (2001) Räddningstjänsten i förändring: ledarskap och metodik för säkerhet och skydd mot olyckor (The fire and rescue service in change: leadership and methodologies for safety and protection against accidents). Räddningsverket

Räddningsverket (2003) Att beställa och utforma räddningsinsatser (Ordering and designing emergency response). Karlstad: Räddningsverket

Smith, P.C., Street, A. (2005) Measuring the efficiency of public services: the limits of analysis. Royal Statistical Society. 168:2:401-417 
Southwick, L., Butler, R. (1985) Fire department demand and supply in large cities. Applied Economics. 17:4:508-526

Stenberg, R. (2012) Effektivitet, säkerhet och pengar. Att hantera skilda effektivitetsperspektiv $i$ räddningstjänsten (Efficiency, safety and money. Dealing with different efficiency perspectives in emergency services). CARER report 2012:4, Linkoping University Electronic Press.

Stenberg, R. (2013) Organisering för trygghet $i$ samhällets tjänst. En fallstudie av Södertörns brandförsvarsförbund (Organizing for safety in the service of society: a case study of Södertörn fire department cooperation). CARER report 2013:8, Linkoping University Electronic Press.

Sund, B., Svensson, L., Rosenqvist, M., Hollenberg, J. (2012) Favorable cost-benefit in an early defibrillation programme using dual dispatch of ambulance and fire services in out-of-hospital cardiac arrest. Eur J Health Econ 13, pp 811-818.

Weinholt, A., Andersson Granberg, T. (2013) Evaluation of enhanced collaboration between fire and rescue services and security officers. Proceedings of the 2013 Information Systems for Crisis Response and Management (ISCRAM) Conference, Baden Baden, GE. 


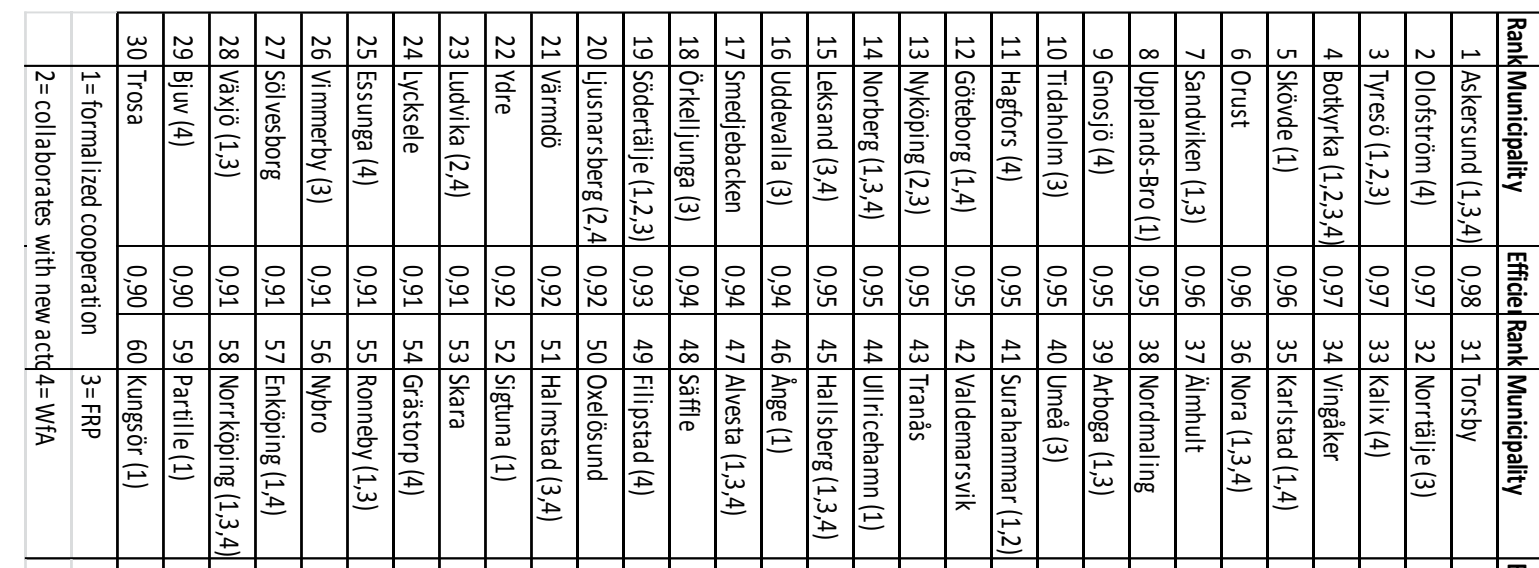

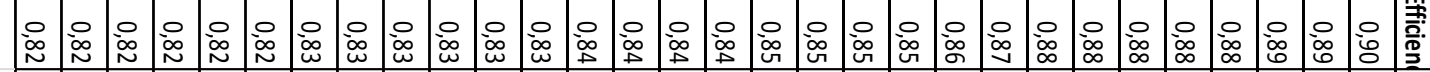

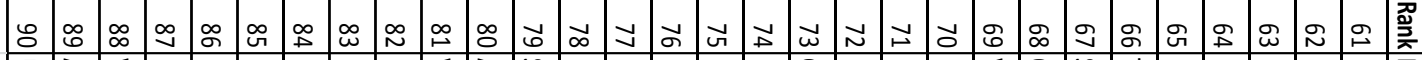
喜 疍:

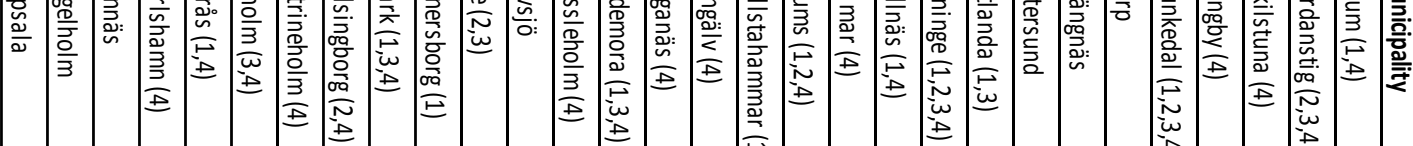

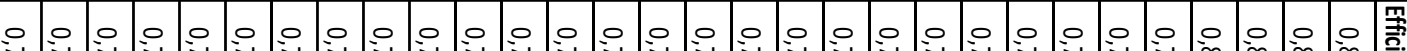

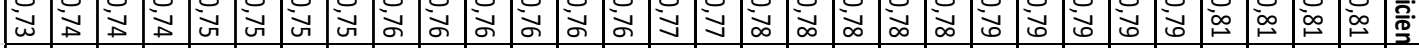

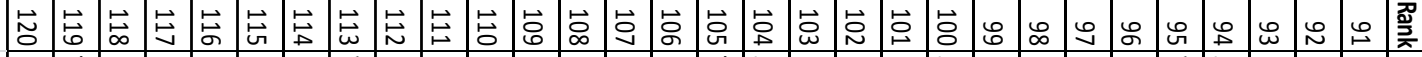

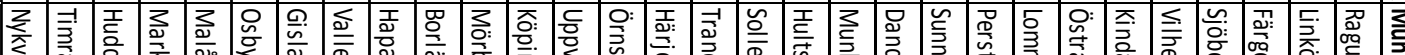

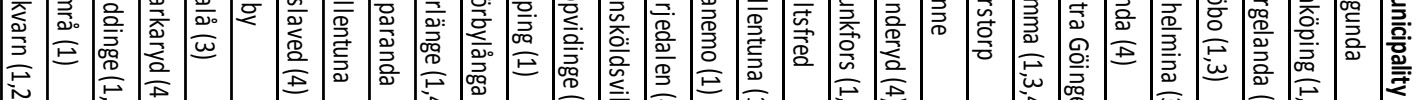

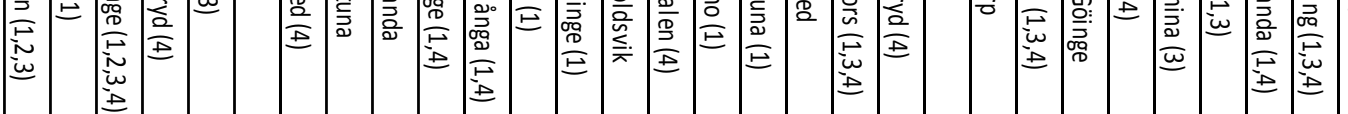

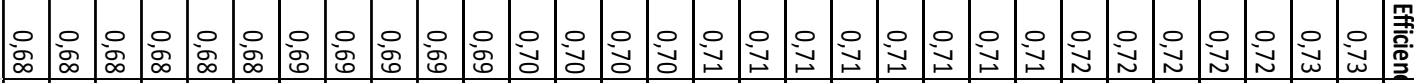

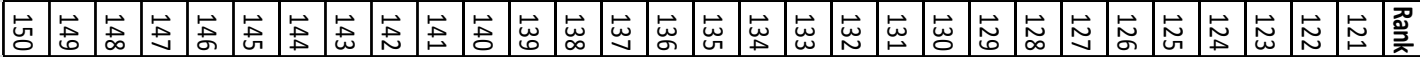
蛋

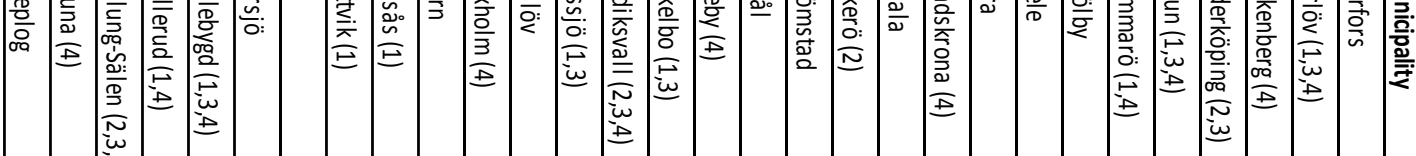

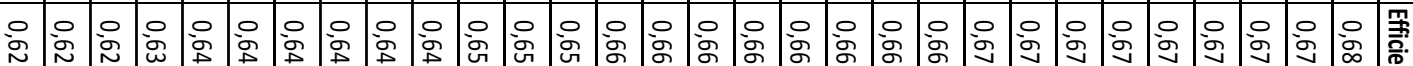

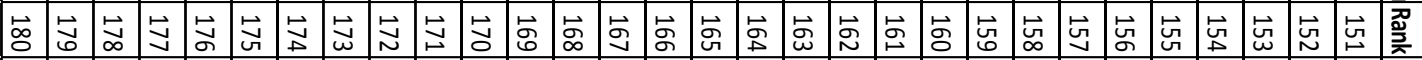

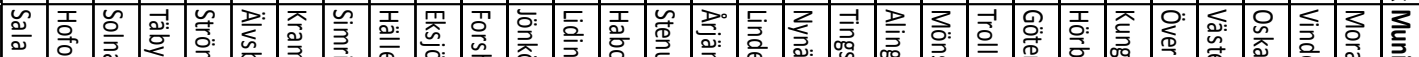

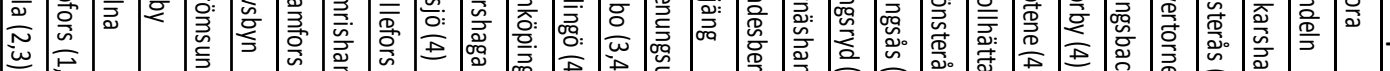

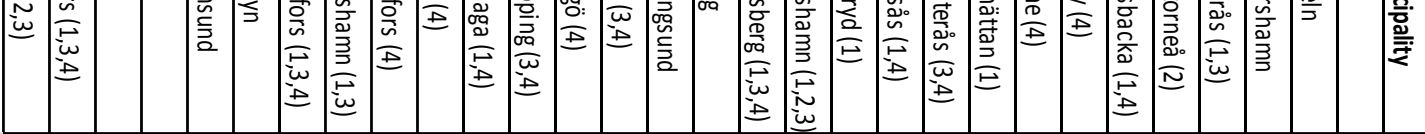

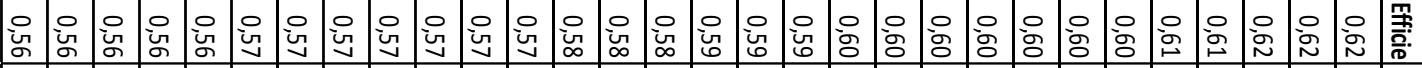

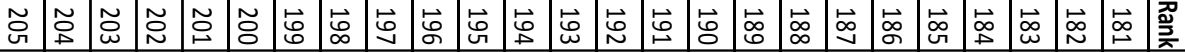

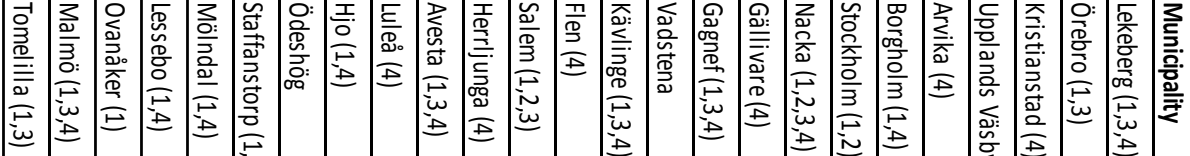

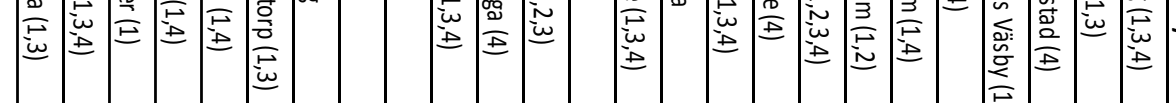
空说 